\title{
Contribution of the cold sector of extratropical cyclones to mean state features in winter
}

Article

Accepted Version

Vanniere, B., Czaja, A. and Dacre, H. (2017) Contribution of the cold sector of extratropical cyclones to mean state features in winter. Quarterly Journal of the Royal Meteorological Society, 143 (705). pp. 1990-2000. ISSN 1477-870X doi: https://doi.org/10.1002/qj.3058 Available at https://centaur.reading.ac.uk/70379/

It is advisable to refer to the publisher's version if you intend to cite from the work. See Guidance on citing.

To link to this article DOI: http://dx.doi.org/10.1002/qj.3058

Publisher: Royal Meteorological Society

All outputs in CentAUR are protected by Intellectual Property Rights law, including copyright law. Copyright and IPR is retained by the creators or other copyright holders. Terms and conditions for use of this material are defined in the End User Agreement.

www.reading.ac.uk/centaur 
Central Archive at the University of Reading

Reading's research outputs online 


\title{
Contribution of the cold sector of extratropical cyclones to mean state features in winter
}

\author{
Benoît Vannière ${ }^{a *}$ Arnaud Czaja ${ }^{b *}$ Helen F Dacre $^{\mathrm{a} *}$ \\ a Department of Meteorology, University of Reading, Reading, United-Kingdom, \\ b Physics Department, Imperial College London, London, United-Kingdom
}

Correspondence to: B. Vannière, Department of Meteorology, University of Reading, Earley Gate, PO Box 243, Reading, RG6 6BB, UK. email: b.vanniere@ reading.ac.uk

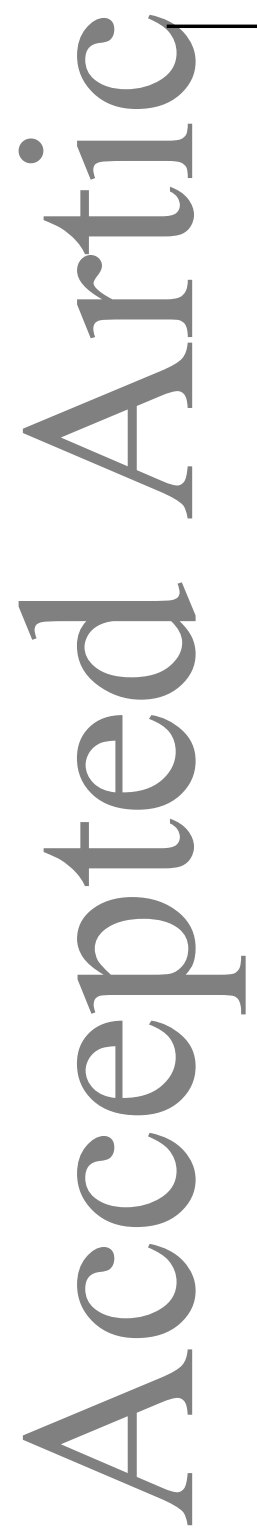

Recent studies have shown that midlatitude air-sea interactions are strongly modulated by synoptic variability. The present study investigates how air-sea interactions over the Gulf-Stream sea surface temperature (SST) front vary in different synoptic regimes. We focus more particularly on the variation of three atmospheric mean state features which are colocated with the SST front in winter : enhanced ascent and precipitation on the warm side of the SST front and enhanced low-level baroclinicity at the entrance of the storm track. These three fields are partitioned depending on whether they occur in the cold sector of extratropical cyclones or in any other synoptic features. The analysis is based on ERA Interim winter data covering the period 1979-2012. Results are twofold. (i) Cold sector precipitation is confined within a $5^{\circ}$ of latitude band south of the SST front and reaches $2 \mathrm{~mm} \mathrm{day}^{-1}$, whereas precipitation occurring outside the cold sector forms a broader spatial pattern. The same partitioning applied to vertical wind shows that the ascent on the warm side of the Gulf Stream is not a feature of the cold sector. These results mean that a significant part of the anchoring effect of the SST front on precipitation occurs via the cold sector and that the observed colocation of ascent and precipitation is not causal, in contrast to what was suggested by previous studies, but is rather the result of two different mechanisms. (ii) The surface heat fluxes and convection occurring in the cold sector restore low-level atmospheric temperature gradients within 2 days after a time maximum of meridional eddy heat flux, such that low-level baroclinicity remains largely unchanged after the passage of an extratropical cyclone. This "cold path mechanism" opens new avenues to understand how SST forces climate variability in the midlatitudes.

Key Words: Cold Sector; Extratropical cyclone; Gulf-Stream; Air-Sea interactions; North Atlantic climate

This article has been accepted for publication and undergone full peer review but has not been through the copyediting, typesetting, pagination and proofreading process, which may lead to differences between this version and the Version of Record. Please cite this article as doi: 10.1002/qj.3058 


\section{Introduction}

During boreal winter, a sharp sea surface temperature (SST) front develops between the warm waters transported by the Gulf Stream and the cold waters of the continental shelf. Observations and numerical experiments have revealed the impact of this SST front on several wintertime climatic features, such as enhanced ascent and precipitation on the warm side of the front (Chelton éal. 2004; Small et al. 2008; Minobe et al. 2008; Kuwanoshida et al. 2010). Furthermore, air-sea interaction processes associated with the SST front have been shown to contribute to the maintenance of low-level baroclinicity in the North Atlantic (Nakamura et al. 2008; Brayshaw et al. 2009). The arguments brought forward to support the SST front-troposphere connection are often based on the colocation of climatological features, which is nbt sufficient on its own to demonstrate a causal link. We propose instead to investigate the mechanism of this connection under different synoptic regimes, which we believe is a more physical approach. To do so, we will use recently developed tools (Vannière et al. 2016b) to partition air-sea interactions depending on whether they occur in the cold sector of extratropical cyclones or in any other synoptic features. Following the American Met orological Society (2016), we define the cold sector as the area within the circulation of an extratropical cyclone, behind the cold front, where cold air advection occurs. This technique was successfully applied to a case study (Vannière et al. 2016a) and will be applied here to ERA Interim climatology. In the remaining part of the introduction, we review the proposed mechanisms controlling the connection of the SST front with the tropospheric circulation, precipitation and baroclinicity, and how his connection is modulated at synoptic time scales.

Minobe et al. (2008) proposed a climatological pathway by which the Gulf Stream SST front can affect tropospheric ascent and precipitation. In this pathway, the temperature of the marine atmospheric boundary layer adjusts to the difference of SST across the front and the resultant pressure anomalies lead to surface wind convergence on the warm side of the front. This surface wind convergence generates upward motion which anchors a sharp band of precipitation. We illustrate this in Fig. This article is protected by copyright. All right
1, where the climatologieal mean (1979-2010) op vertical wind in pressure coordinates $(\omega)$ from ERA Interim forms a band of enhanced ascent on the warm edge of the SST front (Fig. 1(b)), reaching 200hPa (Fig. 1(a)). The Minobe et al. (2008) view combines all the mean climatological features of this region in a plausible mechanism but it is not obvious how it connects to the day-to-day synoptic activity. Indeed, there has been recent claims that, despite the permanent presence of the SST front, airsea interactions over the Gulf Stream are strongly modulated by synoptic activity (2 to 10 days atmospheric variability) in winter (Zolina and Gulev 2003; Hand et al. 2014; Liu et al. 2014; Parfitt and Czaja 2016). To evaluate the sensitivity of the upward motion to synoptic activity, we compare the mean and median vertical wind. In contrast to the mean, the median vertical wind features a subsiding regime on the warm edge of the SST front. This result suggests that the mean upward motion is the residual of frequent episodes of weak subsidence and less frequent episodes of strong ascent (Fig. 1(c,d))

Vannière et al. (2016a) further investigated the mechanism of SST front-troposphere connection at synoptic time scale. In a numerical case study of an extratropical cyclone forced respectively by observed and smoothed SSTs, they showed that the anchoring effect of the SST front on precipitation was mostly related to convective precipitation in the cold sector. The question thus arises to what extent cold sector convective precipitation contributes to the mean climatological precipitation over the Gulf Stream. In a composite of the top 5\% of strongest storms, Vannière et al. (2016b) showed that a significant part of precipitation, albeit weaker than in the warm conveyor belt (WCB), occurred in the cold sector. As $95 \%$ of precipitation in the storm track region is produced by extratropical cyclones (Hawcroft et al. 2012), the cold sector could have a non negligible contribution to climatological precipitation in the Western North Atlantic. If this was the case, we would expect convective precipitation to occur on the warm side of the SST front, where the temperature differential between the surface and the overrunning air mass is essential to force convection. This mechanism would also have the advantage of explaining the strong seasonality of the observed Gulf Stream rain band. Indeed, the anomalous precipitation, which extends far offshore along the SST front during winter, remains confined reserved. 
which could be explained by the fact that there is no cold air outbreak in summer and thus lesser anchoring than in winter. Moreover, by further analysing Minobe et al. (2008) experiments, Kuwano-Yoshida et al. (2010) found that although the anomalous vertical wind associated with the SST front tends to reach the tropopause during summer, it remains confined to the lower half of the troposphere during winter, possibly due to the more stratified troposphere in winter. Finally, a role of the cold sector would be consistent with another finding of Kuwano-Yoshida et al. (2010) who showed that the anomalous precipitation associated with the SST front was exclusively convective (their AGCM has half a degree horizontal resolution), whereas one would expect the warm sector to be associated with both convective and large scale precipitation anomalies.

The effect of the SST front is not only to anchor mesoscale features such as vertical wind and precipitation, but also to favor the development of baroclinic cyclones by maintaining high low-level baroclinicity. Even though land-sea contrast and topography have been shown to play a dominant role in enhancing low-level baroclinicity over the North Atlantic basin, Brayshaw et gl. (2009) suggested the Gulf Stream SST front may also contribute to it. The enhancement of baroclinicity over the SST front energizes eddies and leads to the formation of a downstream storm track as demonstrated by Nakamura et al. (2008) in aquaplanet experiments.

Since extratropical cyclones erode the thermal gradients upon which they develop, the existence of an organised storm track is conditioned to a mechanism restoring baroclinicity. There has been much debate in the literature as to whether sensible heat flux (Hotta and Nakamura 2011) or latent heat release (Hokkins and Valdes 1990; Papritz and Spengler 2015) is the main mechanism restoring baroclinicity. The idea of intermittent bursts of heat transport with a subsequent restoring of potential energy underpins the non-linear oscillator model proposed by Ambaum and Novak (2014). In their study, they showed that the time scale of the restoring processes determines the shape of the oscillation. Ambaum and Novak (2014) attempted to evaluate this time scale based on ERA Interim composites of baroclinicity before and after a maximum of meridional eddy heat flux in the Western North This article is protected by copyright. All right
Atlantic. A large part of the low-level barochmicity was foundo to be restored in the $24 \mathrm{~h}$ following the maximum of eddy heat flux. A similar time scale was found by Nonaka et al. (2009) in the Antarctic Polar Front Zone for a composite of 8 cold air outbreaks, a situation where cold and dry continental air is advected over warmer waters. This rapid restoring suggests that the mechanism might occur within or in association with the eroding process (in the extratropical cyclone). Using a baroclinic wave model, Hoskins and Valdes (1990) proposed that latent heat release in the WCB of the extratropical cyclone itself could modify midtroposphere baroclinicity (as defined by the Eady growth rate) and favor baroclinic cyclogenesis. Conversely, the strong surface sensible heat fluxes of the cold sector could act to restore low-level baroclinicity (Nakamura et al. 2008) via baroclinic adjustment. A recent study by Papritz and Spengler (2015) calculated a full budget of processes setting the slope of the isentropic surfaces in the atmosphere. The displacement of isentropic surfaces by growing baroclinic disturbances was found to reduce the slope of isentropic surfaces. On the contrary, diabatic processes were shown to increase the slope. Interestingly, Papritz and Spengler (2015) showed that the diabatic production of isentropic slope in the low troposphere was associated $80 \%$ of time with cold air outbreaks, supporting a role for the cold sector in restoring baroclinicity.

In summary, this study will investigate how air-sea interactions are modulated by synoptic activity in the Gulf Stream region with three specific goals: (1) estimating the fraction of precipitation occurring in the cold sector, (2) evaluating if the cold sector participates in shaping the region of enhanced ascent and precipitation and (3) assessing the role of the cold sector in restoring high baroclinicity along the SST front. The article is organised as follows: data and methods are presented in section 2 , results in section 3 and discussion in section 4 and conclusion is provided in section 5 .

\section{Data and method}

\subsection{Reanalysis data}

The ECMWF Re-Analysis Interim (ERA Interim) dataset is a reanalysis of the global atmosphere covering the period since 1999, and continuously updated in real time (Berrisford et al. 
2009; Dee et al. 2011). In this study, we used December to February data over the period 1979-2012. It uses 60 levels in the vertical and a spectral truncation of T255 (the reduced Gaussian grid has a $79 \mathrm{~km}$ spacing for surface and other grid-point fields). The data used in this paper has a resolution of $0.75^{\circ}$.

\section{(1)} here are four analysis per day, at 00, 06, 12 and 18 UTC. Predipitation and surface turbulent fluxes are based on forecast data initialised twice a day at 00 and 12 UTC. In order to obtain forecast fields accumulated over the 3 hours immediately following the time of the analysis, we use fluxes accumulated over 3 hours from the forecast initialised at 00 UTC (resp. 12 UTC) to match the 00 UTC (resp. 12 UTC) analysis and the difference of fluxes accumulated over 9 and 6 hours from the forecast initialised at 00 UTC (resp. 12 UTC) to match the 06 UTC (resp. 18 UTC) analysis.

\section{Hawcroft et al. (2012) showed that the magnitude of} precipitation rate was not reliable for the first 3-9 hours of the forecast due to the spin-up effects, whereas the pattern Was not significantly altered. As a result, the sensitivity of the decomposition to the lead time used will be discussed in section 4 . The distinction between convective and large scale precipitation is often argued to be misleading, as the split is essentially determined by model resolution. Nevertheless, we will use this distinction because it can help infer the physical processes leading to precipitation (Kuwano-Yoshida et al. 2010).

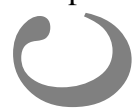

We also use in section 3.4 the ECMWF Operational Analyses from the Year of Tropical Convection (YOTC) dataset. ECMWF available for the period covering May 2009 to April 2011 the forecasts of the process budgets. The tendencies of temperature and humidity will be used to investigate the processes restoring the temperature gradients in the lower troposphere. As there are only two winters in this period, we use 6-hourly outputs from December to March. The forecast of the tendencies of temperature and humidity are initialised once a day, accumulated in time and made available every three hours. In order to obtain tendencies accumulated over 3 hours and This article is protected by copyright. All right
corresponding to the time of the analysis, we take the differeice between two successive lead time of a given forecast (e.g. the tendencies at 06 UTC are obtained from the forecast initialised at 00 UTC and by taking the difference between the accumulated forecast at lead times 9 hours and 6 hours).

\subsection{Cold sector indicator}

To identify the cold sector, we use an indicator combining PV at $975 \mathrm{hPa}$ and surface sensible heat flux (Vannière et al. 2016b). Such an indicator was tested in a composite of 57 extratropical cyclones in the Gulf Stream region, and it allowed a systematic and accurate detection of cold sector precipitation and subsidence (see a detailed discussion in Vannière et al. (2016b)).

Here, locations where a given grid cell $x$ at a given time $t$ has negative $\mathrm{PV}$ at $975 \mathrm{hPa}$ and upward surface sensible heat flux above the threshold value $50 \mathrm{Wm}^{-2}$ is defined as being in the cold sector and noted $C S$. The notation $\overline{C S}$ corresponds to all the other synoptic features. The indicator of the cold sector is defined as follows :

$$
1_{C S}(x, t)= \begin{cases}1 & \text { if }(x, t) \in C S, \\ 0 & \text { if }(x, t) \notin C S,\end{cases}
$$

The contribution to the climatological mean, $\mu$, of a variable $F$ can be expressed as the mean under a given synoptic situation, $m$, times the frequency of this synoptic situation, $P$. This can be written as follows :

$$
\begin{aligned}
& \mu_{C S}(F)=m_{C S}(F) \times P\left(1_{C S}\right) \\
& \mu_{\overline{C S}}(F)=m_{\overline{C S}}(F) \times P\left(1_{\overline{C S}}\right)
\end{aligned}
$$

In the case of precipitation, we want to achieve a partitioning of the total precipitation budget and therefore $\mu$ is calculated. Note that $\mu$ does not reflect the atmospheric state of the atmosphere in a cold sector situation, but rather the contribution of the cold sector to this mean. To estimate the mean atmospheric state in the cold sector, the mean of cold sector $\left(m_{C S}(F)\right)$ is used. In a similar way, the mean atmospheric state outside the cold sector is reserved. estimated using $m_{\overline{C S}}(F)$. 


\section{Results}

\subsection{Case study}

In order to illustrate how precipitation responds to the SST front in the various parts of an extratropical cyclone, we first analyse a case study of an extratropical cyclone which passed over the Gulf Stream region on 27 January 1985. Figure 2a shows total precipitation on 27 January at 00 UTC, when the extratropical cyclone reaches its maximum intensity. One can recognise the classical $\tau$-shape of the WCB with its lower branch wrapping cyclonically around the low pressure center. The WCB is characterised by heavy precipitation rates up to $120 \mathrm{~mm}_{\text {day }}{ }^{-1}$. Another band of precipitation, is observed west of the WCB and lies parallel to the Gulf Stream SST front (black contours). This band of precipitation is located in the cold sector (regions where the cold sector indicator is positive are enclosed in red contours). Figure 2(b) shows concomitant upward motion at $700 \mathrm{hPa}$, which S characteristic of the WCB. In the cold sector, a dipole of ascent/subsidence centred on the SST front is observed. Along the North American coast, neither convection nor upward motion are observed, as air parcels need to accumulate enough heat and moisture for convection to develop (Vannière et al. 2016a). All these results are consistent with those found in Vannière et al. (2016a) and suggest that cold sector convection strongly responds to the SST gradient in ERA Interim too.

We now investigate the evolution of temperature in the lower troposphere as the storm propagates eastward and evaluate the effect that enhanced convection on the warm side of the SST gradient has on the restoration of low-level temperature gradients. Fig. 3 shows equivalent potential temperature $\left(\theta_{e}\right)$ at $950 \mathrm{hPa}$, which characterises warm and cold sector air masses. On 26 January (Fig. 3 (a)), a tongue of warm air starts developing and crosses the SST front between $60^{\circ} \mathrm{W}$ and $50^{\circ} \mathrm{W}$. On 27 January, the warm sector has propagated eastward and the warm tongue has further developed. West of the warm tongue however, the tongue of cold air is less marked, as the cold advection is strongly damped by surface turbulent fluxes (Fig. 3 (b)). On 28 January, isotherms are oriented in the same direction as the SST front again and on This article is protected by copyright. All right same value as on 26 January. This sequence suggests that lowlevel temperature gradients in the atmosphere are restored rapidly by the strong surface fluxes and convection in the cold sector. As high baroclinicity is associated with strong horizontal temperature gradients, we expect low-level baroclinicity to be restored rapidly after the passage of the extratropical cyclone. This is tested in the next paragraph.

A good measure of baroclinicity is the Eady growth rate (Hoskins and Valdes 1990; Woollings et al. 2010), which is calculated as follows:

$$
\sigma=0.31 \frac{f}{N}\left|\frac{\partial u}{\partial Z}\right|
$$

where the Coriolis parameter, $f=2 \Omega \sin \phi, \Omega$, the rotation rate of the Earth, and $\phi$, the latitude and the Brunt-Vaisaila frequency, $N=g \partial \ln \theta / \partial Z, \theta$ is potential temperature, g, the gravitational acceleration, and $Z$ is geopotential height. The height derivatives are evaluated between levels 850 and $700 \mathrm{hPa}$. The Eady parameter has been calculated with instantaneous fields as in Ambaum and Novak (2014).

The instantaneous value of the Eady growth rate is overlaid in red contours on Fig. 3. As seen on Fig. 3(a) and (b), the Eady parameter tends to be high along the warm front of the extratropical cyclone. In the region of warm air advection itself baroclinicity is low, which is consistent with the general idea that horizontal advection destroys temperature gradients and reduces baroclinicity (see Hoskins and Valdes 1990, for instance). Baroclinicity increases again in the cold sector between 27 and 29 January and the region of high baroclinicity, initially confined to the North American coast, moves eastward. From 28 January, the highest baroclinicity values are colocated with the highest SST gradient.

We now analyse the time-evolution of baroclinicity over the Gulf Stream region during the passage of the storm. To do so, we compute time series of the eddy heat flux and baroclinicity tendency by averaging spatially those two fields in the domain $\left[80^{\circ} \mathrm{W}-30^{\circ} \mathrm{W}, 30^{\circ} \mathrm{N}-50^{\circ} \mathrm{N}\right.$ ] (referred to as Gulf Stream region hereafter). The eddy heat flux is calculated between 700 and 925 $\mathrm{hPa}$ by applying a high-pass Lanczos filter with a 10-day cut-off reserved. 
is computed as the time derivative of $\sigma$ and approximated with the finite difference method between two consecutive time steps. To further analyse how the different parts of the storm contribute to the change in baroclinicity, the baroclinicity tendency was partitioned between cold sector $(C S)$ and the remainder of synoptic features, referred to as non cold sector $(\overline{C S})$ hereafter, before computing the spatial average in the domain. All the resulting time series are centred on the maxima of eddy heat flux which occurred on 27 January (Fig. 4(a)). Baroclinicity decreases over the domain before the maximum of eddy heat flux and increases immediately after (Fig. 4(a)). The reduction of baroclinicity occurs in $\overline{C S}$ in phase with the maximum of eddy heat flux and most likely due to horizontal advection. Conversely, the increase of baroclinicity occurs in $C S$, after the maximum eddy heat flux, when surface turbulent heat fluxes in the cold sector are the strongest Fig. 4 (b). This sequence of events supports the idea that for this particular extratropical cyclone, the strong surface heat fluxes and convection in the cold sector played a key role in restoring low-level baroclinicity.

In the following subsections, we evaluate the distribution and the amount of precipitation, vertical motion and baroclinicity occurring in the cold sector and outside the cold sector in the climatology.

\subsection{Precipitation}

The ERA Interim climatological mean precipitation, shown on Fig. 5 (a), was partitioned between the cold sector $(C S)$ and the non cold sector features $(\overline{C S})$, in Fig. 5 (c) and (b), respectively. The/colour bars are different in each panel in order to highlight the difference in meridional extent of the precipitation pattern. In the Gulf Stream region (as defined in the previous section) $C S$ precipitation represents $13.5 \%$ of the total precipitation. Despite representing only a small fraction of the total precipitation, $C S$ spatial distribution may influence the pattern of total precipitation. Indeed, precipitation occurring in $C S$ forms a band following the line of the SST front and reaches up to $2 \mathrm{~mm} \mathrm{day}^{-1}$ on the warm side of the SST front, i.e. south of the maximum SST gradient. In contrast, precipitation occurring in $\overline{C S}$ forms a more widespread pattern over the SST front. The latter peaks south of the SST front This article is protected by copyright. All right
at $37^{\circ} \mathrm{N}$ and has an amplitude of $5 \mathrm{~mm}$ day . In order to meastre the difference of spatial spread between precipitation occurring in $C S$ and $\overline{C S}$, we compare the area where mean precipitation exceeds $50 \%$ of the maximum value. This area is given as a fraction of the Gulf Stream region and is called $\rho$. The value of $\rho$ was found to be $22.2 \%$ and $84.6 \%$ in $C S$ and $\overline{C S}$, respectively, confirming the larger confinement of $C S$ precipitation.

We further decompose the precipitation into convective and large scale components (Fig. 6). The band of precipitation in the cold sector comprises $70 \%$ convective precipitation. The remaining $30 \%$ forms a band of large scale precipitation also following the SST front. However, the large scale precipitation occurring in the cold sector must be interpreted with some caution. Indeed as described by Vannière et al. (2016b), the cold sector indicator can capture some large scale precipitation from the WCB due to the vertically sloped nature of the cold front. The precipitation in $\overline{C S}$ splits into convective precipitation on the south side of the front and large scale precipitation north of it, corresponding to the entrance and the upper branch of the WCB respectively. To test whether an incorrect attribution of large scale precipitation to the cold sector could change our conclusions on the different spread of precipitation in $C S$ and $\overline{C S}, \rho$ was calculated again for convective precipitation in the cold sector only and for the rest of precipitation. The new values of $\rho$ are $24.2 \%$ and $78.6 \%$ respectively, implying that our results are not sensitive to this issue.

\subsection{Vertical wind}

The cold sector mask is now applied to ERA Interim vertical wind at $700 \mathrm{hPa}$. The time mean vertical wind (Fig. 7 (a)) is the result of a balance between the contributions of $C S(\mathrm{~b})$, dominated by subsidence, and $\overline{C S}$ (c). The two contributions largely cancel out, as their sum is one order of magnitude less than each taken separately. It is clear that in $\overline{C S}$, ascent is strongest on the warm side of the SST front. This is explained by the strong adiabatic ascent along the sloped isentropic surfaces originating from the SST front (Parfitt and Czaja 2016). Interestingly, the cold sector subsidence is weakest south of the front. We also find that $25 \%$ of the time cold sector air is ascending on the warm side of the front (not shown). This leads us to evaluate vertical wind in the reserved more specific situation where convection occurs in the cold sector. 
In Fig. 7 (d) we composite cold sector situations with convective precipitation greater than $5 \mathrm{~mm}$ day $^{-1}$. In those situations, ascent dominates on the warm edge of the SST front and is equal to $20 \%$ of total vertical ascent (compare Fig. 7 (a) and (d)). This cold sector ascent is consistent with the circulation cell crossing the SST front described in the cold sector of an extratropical cyclone passing over the Gulf Stream in Vannière et al. (2016a).

In conclusion, the enhancement of mean ascent and precipitation on the warm side of the SST front occurs through two different synoptic features, respectively the cold and non cold sector situations. It is likely that the strong ascent on the warm side of the front is mainly set by the ascending motion in WCBs. However, this cannot be definitively stated as the warm sector of extratropical cyclone is only one of several synoptic features contained in the non cold sector composite. Cold sector precipitation is associated with ascent but this ascent represents only a small fraction of the total and cannot be viewed as the primary contribution setting the banded pattern of vertical wind.

\subsection{Baroclinicity}

In section 3.1, we showed in a case study that convective processes together with surface heat fluxes could explain the rapid increase of low-level baroclinicity in the wake of the extratropical cyclone. As section 3.2 showed that cold sector convection was favoured on the warm side of the SST front at the expense of the cold side, we want to evaluate what effect this has on the restoration of temperature gradients and baroclinicity in the lower troposphere. To evaluate the impact of convection, we make use of the ERA Interim YOTC dataset which includes forecasts of temperature and specific humidity tendencies. As there are only two winters in the dataset, we use 6-hourly data and a series of specific criteria to define the composite. The composite is build as follows: we calculate time series of meridional eddy heat flux between 925 and $700 \mathrm{hPa}$, as in section 3.1, and SLP by averaging spatially the two fields in the box $\left[60-50^{\circ} \mathrm{W}, 30-50^{\circ} \mathrm{N}\right]$; we select all time steps for which the eddy heat flux is in the top $15 \%$ strongest and SLP in the $15 \%$ lowest, thus identifying extratropical cyclones. We find that 45 time steps meet the criteria. Simultaneously, the range of longitudes 70 and $60^{\circ} \mathrm{W}$, where the SST front tends to be the most zonally oriented, is expected to be in the cord sector. Figure 8 (a) shows the meridional gradient of $\theta_{e}\left(\partial_{y} \theta_{e}\right)$ averaged between 1000 and $700 \mathrm{hPa}$ and 70 and $60^{\circ} \mathrm{W}$. A few days before the cyclone is identified, the maximum of $\partial_{y} \theta_{e}$ is at its climatological position at $40^{\circ} \mathrm{N}$. One day before, the increase of $\partial_{y} \theta_{e}$ corresponds to the warm front which tends to migrate toward the North as the extratropical cyclone does. It is interesting to see the split into two gradient maxima after lag 0 . A southern branch is the signature of the cold front, pushed southward by the cold sector advection. Another maximum stays around the climatological position of the maximum $\partial_{y} \theta_{e}$ and indicates that a mechanism is at play to maintain the maximum gradient at this position. We now define the mean latitude of the maximum of $\partial_{y} \theta_{e}$ at each time by identifying, at each longitude, the latitude of the maximum of $\partial_{y} \theta_{e}$ and averaging this zonally in the range of longitude $\left[70^{\circ} \mathrm{W}-60^{\circ} \mathrm{W}\right]$. Note that we do not expect the maximum of the zonal mean to be the same as the zonal mean of the maximum of $\partial_{y} \theta_{e}$, hence the highest values of the colour field does not match the position of the black line on Fig. 8 (a). The mean latitude of the maximum of $\partial_{y} \theta_{e}$ gives a time scale of 2 to 3 days for the low-level temperature gradient to be repositioned to its climatological mean.

In Fig. 8 (b)-(c), we investigate which processes lead to reposition the gradient of $\theta_{e}$ to its climatological mean. To do so, we first compute $\theta_{e}$ total tendency $\left(\dot{\theta}_{e}\right)$ using the total tendencies of temperature and specific humidity from the YOTC dataset; we then apply the cold sector mask to $\dot{\theta}_{e}$; and finally, we take the difference of $\dot{\theta}_{e}$ between the two ranges of latitude $\left[30^{\circ} \mathrm{N}-40{ }^{\circ} \mathrm{N}\right]$ and $\left[40^{\circ} \mathrm{N}-50^{\circ} \mathrm{N}\right]$, i.e. between south and north of the climatological position of maximum gradient of $\theta_{e}$, and refer to this difference as $\Delta_{S / N} \dot{\theta}_{e}$ hereafter. Thus calculated, $\Delta_{S / N} \dot{\theta}_{e}$ indicates how the gradient of temperature evolves in the lower atmosphere: when positive, the atmospheric temperature gradient is increased over the SST front and when negative, the atmospheric temperature gradient is reduced. We further decompose the total tendency into tendencies due to dynamics (i.e. advection), turbulent diffusion (i.e. the unresolved small scale vertical transport of heat and moisture) and convection, as we find that they are the only processes to contribute significantly reserved,
to a nownsouth difference at the levels considered. We also 
decompose the tendencies into two levels $1000-850 \mathrm{hPa}$ and 850 $700 \mathrm{hPa}$, as convection is expected to redistribute $\dot{\theta}_{e}$ between the lower and upper part of the boundary layer. At lag 0 , the total tendency is negative at all levels (Fig. 8 (b) and (c)) and the atmospheric temperature gradient is reduced over the SST front (Fig. 8 (a)). Conversely, at lag 1 day, the total tendency becomes positive (Fig. 8 (b) and (c)) and the atmospheric temperature gradient is increased over the SST front. From lag 0 to 2 days, the cold sector advection tends to strongly reduce the difference of $\theta_{e}$ on both side of the SST front in agreement with our interpretation of Fig. 8 (a). Simultaneously, boundary layer diffusion acts to reestablish this difference in the lower part of the boundary layer $(1000-850 \mathrm{hPa})$. The effect of convection is to redistribute $\theta_{e}$ vertically, so that the north-south difference of $\theta_{e}$ increases in the upper part of the boundary layer (850-700 hPa), while decreasing in the lower part (1000-850 hPa).

Now that we have shown that the gradient of moist potential temperature is restored to its climatological position over the SST front in the cold sector by boundary layer diffusion and convection, we investigate if baroclinicity, which is related to meridional temperature gradients, behaves in a similar way. Figure 9 shows the Eady growth rate (a), its mean value in $C S$ (b) and $\overline{C S}$ (c) and the percentage change between $C S$ and $\overline{C S}$ (d). The mean Eady growth reaches its highest values over the maximum of the SST gradient. The same colocation happens when the subset of $C S$ is considered. In $\overline{C S}$, however, the maximum values cceur slightly north of the SST front, which could be due to the advection of the warm front of extratropical cyclones by southerly winds in the warm sector (note that we showed in section 3.1 that the warm front was detected by the Eady growth rate). South of he SST front, baroclinicity is larger in $C S$ than for the remaining situations by an excess of 10 to $30 \%$ (Fig. 9 (d)). These results are compatible with a restoring of baroclinicity over the highest SST gradient via the cold sector.

To ascertain the scenario that baroclinicity is restored in the cold sector, we analyse the time-evolution of baroclinicity during the passage of an extratropical cyclone as in Fig. 4 but for a composite including a large number of storms. The composite is build by calculating a 6-hourly time series of meridional eddy This article is protected by copyright All right
heat fluxes between 925 and 700 hPa averagelin the Gulf Stream region for all DJF of the ERA Interim period and retaining all time steps belonging to the top $10 \%$ of strongest meridional eddy heat fluxes. All events are centred on the maxima of eddy heat flux before averaging the composite. Results are presented in Fig. 10 (a). As in the case study (section 3.1), there is a strong decrease and increase of low-level baroclinicity (see green curve) before and after a burst of eddy heat flux (black curve). The contributions of $C S$ (blue line) and $\overline{C S}$ (red line) to the baroclinicity tendency are also presented in Fig. 10 (a). At all times, the baroclinicity tendency is negative in $\overline{C S}$ and positive in $C S$, showing the preferential role of the cold sector to restore baroclinicity. Around the maximum of eddy heat flux, variations of baroclinicity are interpreted as follows. When the eddy heat flux reaches its maximum, the horizontal mixing induced by the extratropical cyclone reduces temperature gradients and therefore the mean baroclinicity in the domain. This reduction occurs primarily due to horizontal advection outside the cold-sector $(\overline{C S})$. Note that the contribution of $\overline{C S}$ to total surface heat fluxes does not vary much before and after the passage and is less than $70 \mathrm{Wm}^{-2}$ at all times (see red curve in Fig. 10 (b)). As the cyclone moves further eastward, a large part of the domain is in the cold sector, where strong surface turbulent fluxes occur, $160 \mathrm{Wm}^{-2}$ on average (see Fig. 10 (b)). The differential turbulent fluxes on both sides of the SST front lead to an increase of cold sector baroclinicity (blue curve on Fig. 10 (a)). After 2 days, the net baroclinicity of the domain is back to its value before the passage of the storm (not shown). Over all, the baroclinicity evolves in the composite in a similar manner as in the case study presented in section, with positive baroclinicity tendency in the cold sector and in the warm sector (section 3.1).

We further investigate whether the restoration of baroclinicity in the cold sector is caused by a change in stability $(N)$ or in wind shear $\left(\left|\frac{\partial u}{\partial Z}\right|\right)$. At least two mechanisms can be considered : a decrease of stability in response to the strong surface turbulent fluxes or an increase of wind shear $\left(\left|\frac{\partial u}{\partial Z}\right|\right)$, related to horizontal temperature gradients by the thermal wind balance, in response to the differential heating on both sides of the SST front. The respective role of wind shear and stability is evaluated by replacing their climatological values in the calculation of $\sigma$. We reserved. 
strong wind shear increases baroclinicity in $C S$ in comparison to $\overline{C S}$, whereas the enhanced stability above the boundary layer tends to decrease it slightly (not shown). The higher stability in the cold sector is explained by the strong stratification of the free troposphere above the boundary layer.

\section{Discussion}

As a quantitative partitioning is undertaken in this study, it seems important to assess the sensitivity of our results to the methodology.

First, the reported biases in ERA Interim precipitation associated to the model spin-up may alter the proportion of precipitation occurring in the cold sector. To test whether our conclusions are sensitive to the spin-up, we carried out the same partitioning as in section 3.2 independently for the forecast fields after a 3-hour lead time (00 and 12 UTC) and 9 hour lead time (06 and 18 UTC). To do so, we use forecast data initialised at 12 UTC and take the difference of the accumulated fields over 6 and 9 hours. The proportion of precipitation falling in the cold sector when only 3 hour lead time is used (13.3\%) is not significantly different from that when only 9 hour lead time is used $(13.7 \%)$. Thus the choice of the lead time does not seem to have much effect on the proportion of cold sector precipitation.

Secondly, choosing multiple criteria to define the cold sector mask is always a trade-off between accuracy and systematicity as discussed in Vannière et al. (2016b). Moreover, the ability of a given criterium to detect $C S$ may differ spatially. For example, surface sensible heat flux is on average larger on the warm side of the SST front, where it passes more often the threshold value defining CS. Thus, the cold sector is more often detected on the warm edge of the SST front than it is on the cold edge Fig. 11. This might reinforce the contrast between the north and south edge of the SST front and amplify the banded pattern of precipitation. We tested how the addition of the criterium based on sensible heat flux in $C S$ diminishes the proportion of cold sector precipitation detected. Therefore, we recomputed the mask with the PV criterium only : the proportion of precipitation falling in the cold sector is now $28.7 \%$, and must be compared to $22.2 \%$ This article is protected by copyright. All rights
when both $P$ and surface sensible heat flux are used. We expect the true amount of precipitation in the cold sector to lie between those two values.

Finally, we discuss our conclusions on the role of the cold sector in restoring low-level baroclinicity. This conclusion relies both on the fact that $C S$ contributes to the restoration of baroclinicity and that we did not find a significant difference of baroclinicity a few days before and after the maximum of eddy heat flux. We note that this difference was marginal in Ambaum and Novak (2014) and we found that it is sensitive to the criteria retained to build the composite. Hence, we do not deny that other physical processes may participate in the restoration of baroclinicity on time scale of a few days as suggested by Ambaum and Novak (2014), but results suggest that the main source of restoration of baroclinicity occurs in the cold sector of the storm itself. This result is consistent with Nonaka et al. (2009) who showed that along SST fronts in the southern Indian Ocean, lowlevel horizontal temperature gradients were restored in 24 hours after the passage of a storm.

\section{Summary and conclusions}

The cold sector of extratropical cyclones in ERA Interim data is found to be dominated by precipitation of convective type, tightly linked to the Gulf Stream SST front. During convective events, a dipole of ascent/subsidence at $700 \mathrm{hPa}$, centred on the SST front, is observed. To assess the significance of cold sector contribution to climatological precipitation, ERA Interim precipitation has been partitioned depending on whether it occurs in the cold sector of extratropical cyclones or in the remainder of synoptic features. A PV indicator described in Vannière et al. (2016b) has been used for the partitioning. We find that non cold sector precipitation forms a broad pattern peaking on the warm side of the SST front. This pattern resembles the frequency of WCB precipitation presented in Pfahl et al. (2014) (see their Fig. 7a.). On the contrary, cold sector precipitation is confined within $5^{\circ}$ of latitude in a sharp band following the Gulf-Stream SST front. These results suggest that a significant part of the anchoring effect of the SST front on precipitation is via the cold sector.

As the observed band of precipitation has often been associated with vertical ascent on the warm side of the front, the PV indicator reserved. 
the cold sector. The contributions from these two parts of the extratropical cyclone largely cancel out to set the mean pattern.

These results demonstrate the importance of synoptic variability in controlling how the sea surface connects to the troposphere. Interestingly, cold sector precipitation has the same amplitude as the reduction of precipitation in response to a smoothing of the SST gradients (Minobe et al. 2008). It is thus plausible that the response of the precipitation to a smoothing of the SST front occurs mostly in the cold sector. In contrast, the strong ascent on the warm side of the SST front can not be attributed solely to the cold sector, as the stronger vertical wind south of the SST front is also seen outside the cold sector. Hence no direct causal link between ascent and precipitation on the warm side of the Gulf Stream can be made. It is nevertheless of interest to emphasise that an indirect link between precipitation and vertical wind still exists : convective adjustment leads to a steepening of isentropic surfaces in the cold sector which can generate stronger adiabatic ascent in the warm sector of ubsequent storms.

This study also highlights the contribution of cold sector processes in setting low-level baroclinicity and preconditioning the atmosphere for the development of subsequent storms. The cold sector mask was applied to partition low-level baroclinicity tendency and surface heat fluxes for a composite of strongest meridional eddy heat fluxes. Baroclinicity increase was shown to occur in the cold sector after the maximum of eddy heat flux and concurrently with strong surface heat fluxes. Once restored, baroclinicity increased passively in the non cold sector as the cold sector moves away. In the entire domain, baroclinicity was restored after approximately two days. Moist potential temperature tendencies demonstrated the role of differential surface turbulent fluxes and convective activity on both sides of the SST front in restoring the lower atmosphere temperature gradients in the cold sector of extratropical cyclones.

This finding supports the mechanism of the ocean baroclinic adjustment (Nakamura et al. 2008), which occurs in conjunction with large sensible and latent heat fluxes on the warm side of the front (Taguchi et al. 2009; Nonaka et al. 2009) but relates it more clearly to the intermittency of atmospheric disturbances. The 48 This article is protected by copyright. All right of meridional eddy heat flux is of the same order as the time scale found by Nonaka et al. (2009) in a composite of 8 cold air outbreaks in the Antarctic Polar Front Zone. This suggests that low-level baroclinicity is left relatively unchanged by the passage of a cyclone. Our results underpins the recent study by Papritz and Spengler (2015) showing that the steepening of isentropic slopes due to diabatic heating occurs primarily during cold air outbreaks. Even though they did not decompose the respective contribution of latent heat release versus sensible heat flux, the presence of precipitation in the cold sector, even weak, might imply a significant contribution of the former. Indeed, as explained by Papritz and Spengler (2015), the effect of diabatic heating on isentropic slopes also depends inversely on static stability, which is relatively low in the cold sector. More work is needed to evaluate precisely the role of latent heat release in restoring baroclinicity in the cold sector.

In order to distinguish between the direct and indirect effects of the SST front on the ascent in the warm sector and to evaluate how the restoration of baroclinicity in the cold sector favours the anchoring of the storm track, new approaches need to be developed. One possibility is to apply an interactive mask in a CGCMs which would modulate air-sea fluxes in the cold and warm sectors. Such an interactive masking is under development and will be the object of another study.

\section{Acknowledgement}

B. Vannière was funded by the Natural Environment Research Council through the grant NE/J023760/1. The ECMWF is acknowledged for providing access to the ERA Interim and YOTC dataset. We thank three anonymous reviewers for their insightful comments and suggestions which greatly helped improve the manuscript.

\section{References}

Ambaum MH, Novak L. 2014. A nonlinear oscillator describing storm track variability. Quarterly Journal of the Royal Meteorological Society 140(685): 2680-2684.

American Meteorological Society. 2016. Cold sector. Glossary of Meteorology

Berrisford P, Dee D, Fielding K, Fuentes M, Kallberg P, Kobayashi S, Uppala reșerved. 
Brayshaw DJ, Hoskins B, Blackburn M. 2009. The basic ingredients of the north atlantic storm track. part i: Land-sea contrast and orography. Journal of the Atmospheric Sciences 66(9): 2539-2558.

Chelton DB, Schlax MG, Freilich MH, Milliff RF. 2004. Satellite measurements reveal persistent small-scale features in ocean winds. Science 303(5660): 978-983.

Dee D, Uppala S, Simmons A, Berrisford P, Poli P, Kobayashi S, Andrae U, Balmaseda M, Balsamo G, Bauer P, et al. 2011. The era-interim reanalysis: Configuration and performance of the data assimilation system. Quarterly Journal of the royal meteorological society 137(656): 553-597.

Hand R, Keenlyside N, Omrani NE, Latif M. 2014. Simulated response to inter-annual sst variations in the gulf stream region. Climate dynamics $\mathbf{4 2}$ (3$4): 715-731$.

Hawcroft M, Shaffrey L, Hodges K, Dacre H. 2012. How much northern hemisphere precipitation is associated with extratropical cyclones? Geophysical Research Letters 39(24).

Hoskins BJ, Valdes PJ. 1990. On the existence of storm-tracks. Journal of the atmospheric sciences 47(15): 1854-1864.

Hotta D, Nakamura H. 2011. On the significance of the sensible heat supply from the ocean in the maintenance of the mean baroclinicity along storm tracks. Journal of Climate 24(13): 3377-3401.

Kuwano-Yoshida A, Minobe S, Xie SP. 2010. Precipitation response to the gulf stream in an atmospheric gcm*. Journal of Climate 23(13): 3676-3698.

Liu JW, Xie SP, Norris JR, Zhang SP. 2014. Low-level cloud response to the gulf stream front in winter using calipso*. Journal of Climate 27(12): 44214432.

Minobe S, Kuwano-Yoshida A, Komori N, Xie SP, Small RJ. 2008. Influence of the gulf stream on the troposphere. Nature 452(7184): 206-209.

Minobe S, Miyashita M, Kuwano-Yoshida A, Tokinaga H, Xie SP. 2010. Atmospheric response to the gulf stream: seasonal variations*. Journal of Climate 23(13): 3699-3719.

Nakamura H, Sampe T, Goto A, Ohfuchi W, Xie SP. 2008. On the importance of midlatitude oceanic frontal zones for the mean state and dominant variability in the tropospheric circulation. Geophysical Research Letters $35(15)$.

Nonaka M, Nakamura H, Taguchi B, Komori N, Kuwano-Yoshida A, Takaya 2009. Air-sea heat exchanges characteristic of a prominent midlatitude oceanic front in the south indian ocean as simulated in a high-resolution coupled gcm. Journal of Climate 22(24): 6515-6535.

Papritz L, Spengler T. 2015. Analysis of the slope of isentropic surfaces and its tendencies over the north atlantic. Quarterly Journal of the Royal Meteorological Society 141(693): 3226-3238.

Parfitt R, Czaja A. 2016. On the contribution of synoptic transients to the mean atmospheric state in the gulf stream region. Quarterly Journal of the Royal Meteorological Society .

Pfahl S, Madonna E, Boettcher M, Joos H, Wernli H. 2014. Warm conveyor relevance for precipitation. Journal of Climate 27(1): 27-40.

Small R, Xie S, ONeill L, Seo H, Song Q, Cornillon P, Spall M, Minobe S, et al. 2008. Air-sea interaction over ocean fronts and eddies. Dynamics of Atmospheres and Oceans 45(3): 274-319.

Taguchi B, Nakamura H, Nonaka M, Xie SP. 2009. Influences of the kuroshio/oyashio extensions on air-sea heat exchanges and storm-track activity as revealed in regional atmospheric model simulations for the 2003/04 cold season*. Journal of Climate 22(24): 6536-6560.

Vannière B, Czaja A, Dacre H, Woollings T. 2016a. A "cold path" for gulf stream-troposphere connection. Journal of Climate (2016).

Vannière B, Czaja A, Dacre H, Woollings T, Parfitt R. 2016b. A potential vorticity signature for the cold sector of winter extratropical cyclones. Quarterly Journal of the Royal Meteorological Society 142(694): 432-442.

Woollings T, Hoskins B, Blackburn M, Hassell D, Hodges K. 2010. Storm track sensitivity to sea surface temperature resolution in a regional atmosphere model. Climate dynamics 35(2-3): 341-353.

Zolina O, Gulev SK. 2003. Synoptic variability of ocean-atmosphere turbulent fluxes associated with atmospheric cyclones. Journal of climate 16(16): 2717-2734. 

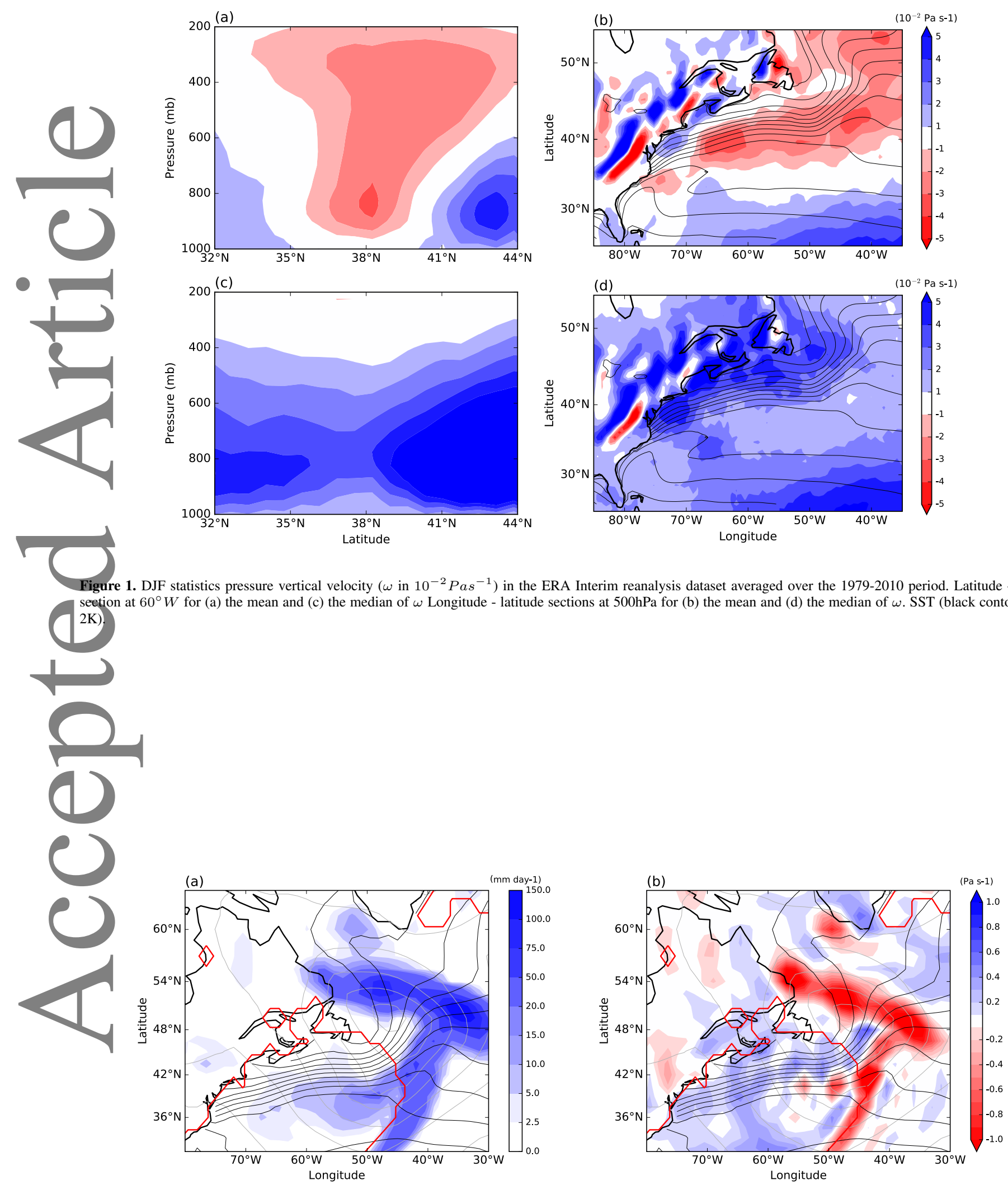

Figure 2. Case of an extratropical cyclone over the Gulf Stream region at 00 UTC on 27/01/1985 (a) total precipitation (blue), sea-level pressure (grey contours, every 5 $\mathrm{hPa}$ ), SST (black contours, every $2 \mathrm{~K}$ ) and cold sector mask (i.e. $1_{C S}$ in red contours); (b) same (a) but shadings represent vertical velocity in pressure coordinates at 700 $\mathrm{hPa}\left(\mathrm{Pa} \mathrm{s}^{-1}\right)$. 
(a) $26 / 01 / 1985$

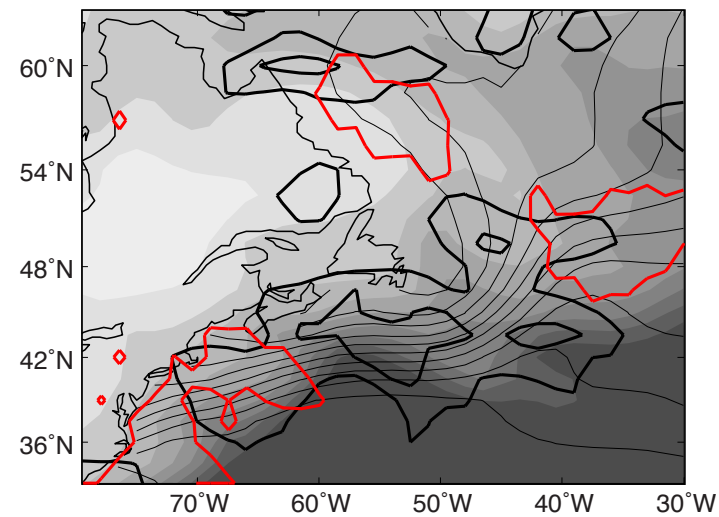

(c) $28 / 01 / 1985$

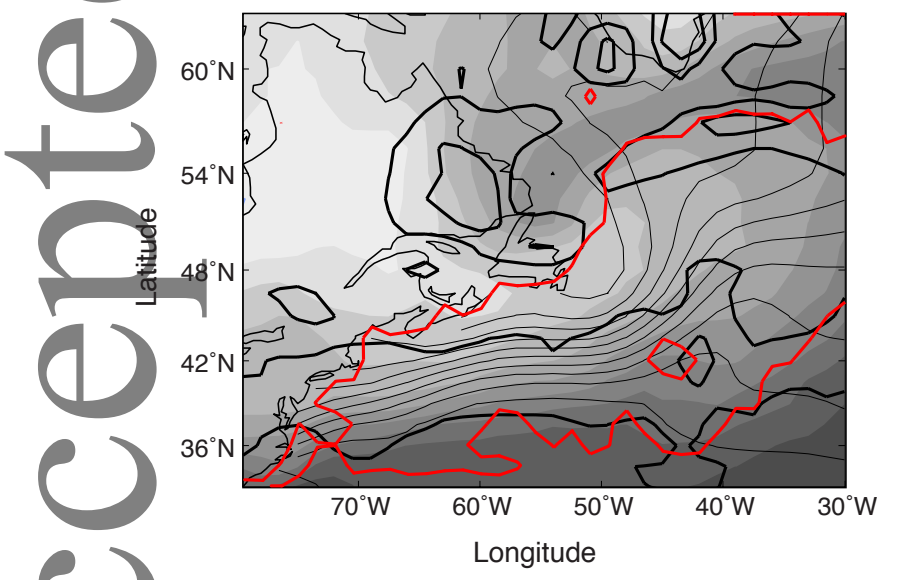

(b) $27 / 01 / 1985$

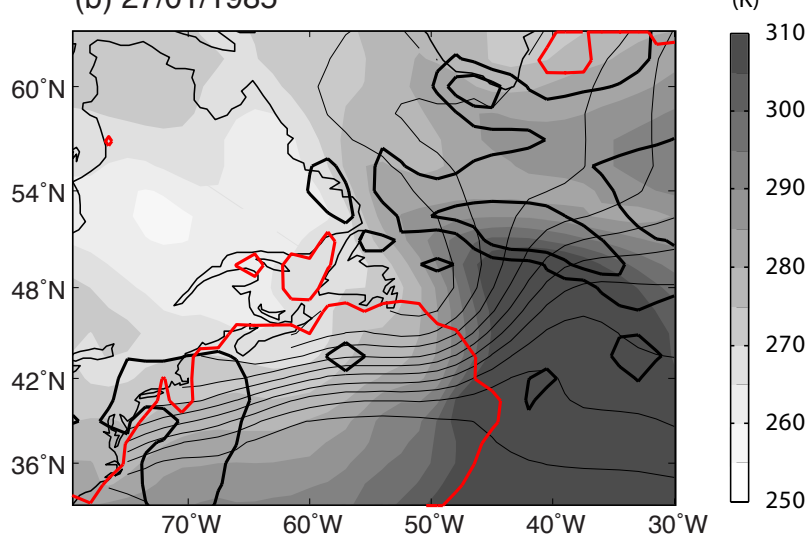

(d) $29 / 01 / 1985$

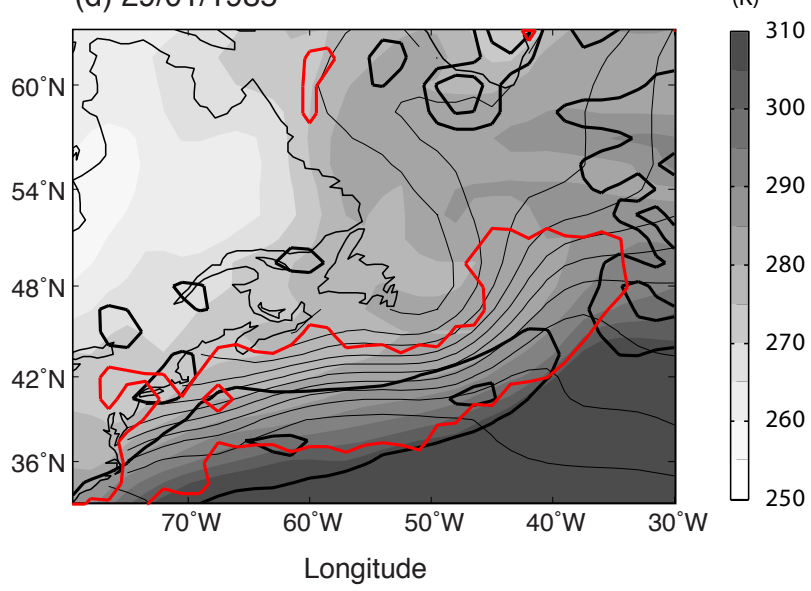

Figure 3. Evolution of equivalent potential temperature (gray shadings), the Eady parameter (thick black contours, every 1 day ${ }^{-1}$ ), SST (fine black contours, every $2 \mathrm{~K}$ ) and cold sector mask (i.e. $1_{C S}$ in red contours), at 00 UTC (a) on 26 January, (b) on 27 January when the extratropical cyclone reaches its maximum intensity, (c) on 28 January and (d) on 29 January.

This article is protected by copyright. All rights reserved. 
(a)

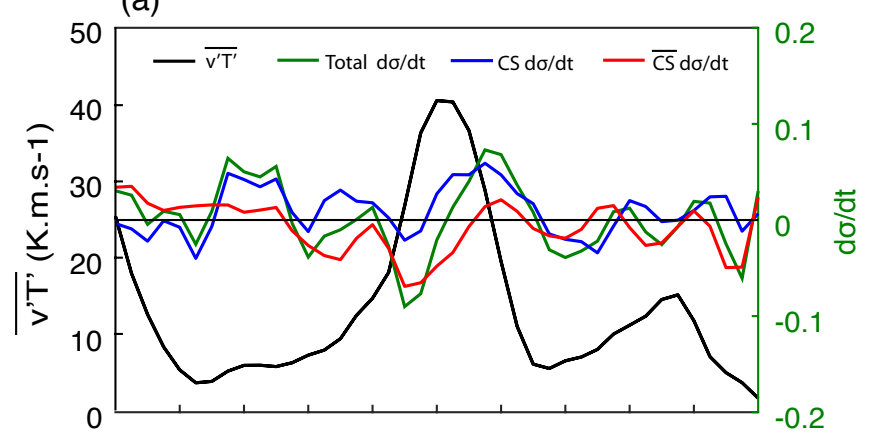

(b)

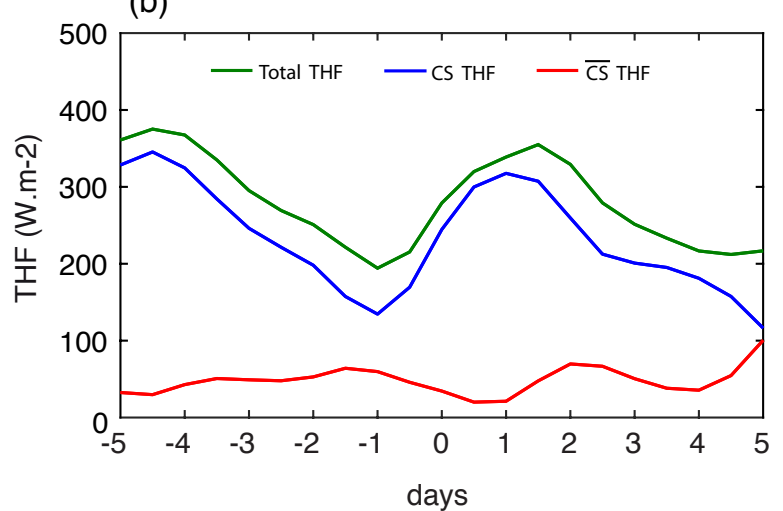

Figure 4. (a) Evolution around the maximum of meridional eddy heat flux at $850 \mathrm{hPa}$ (black curve) which occurred on 27 January 1985 of the tendency of baroclinicity at $775 \mathrm{hPa}$ (green curve in $\left.d a y^{-1}(6 \text { hours })^{-1}\right)$, the contribution of cold sector situations to the tendency of baroclinicity, i.e. $\mu_{C S}(\sigma)$, (blue curve) and the contribution of non cold sector situations, i.e. $\mu \overline{C S}(\sigma)$ (red curve). (b) Evolution for the same composite of the total surface heat flux (green), the contribution of cold sector situations to total heat flux, i.e. $\mu_{C S}(T H F)$, (blue curve) and the contribution of non cold sector situations, i.e. $\mu_{\overline{C S}}(T H F)$, (red curve). All quantities are averaged in the domain $\left[80^{\circ} \mathrm{W}-30^{\circ} \mathrm{W}, 30^{\circ} \mathrm{N}-50^{\circ} \mathrm{N}\right]$. Time axis is given in days with respect to 27 January 1985 . 

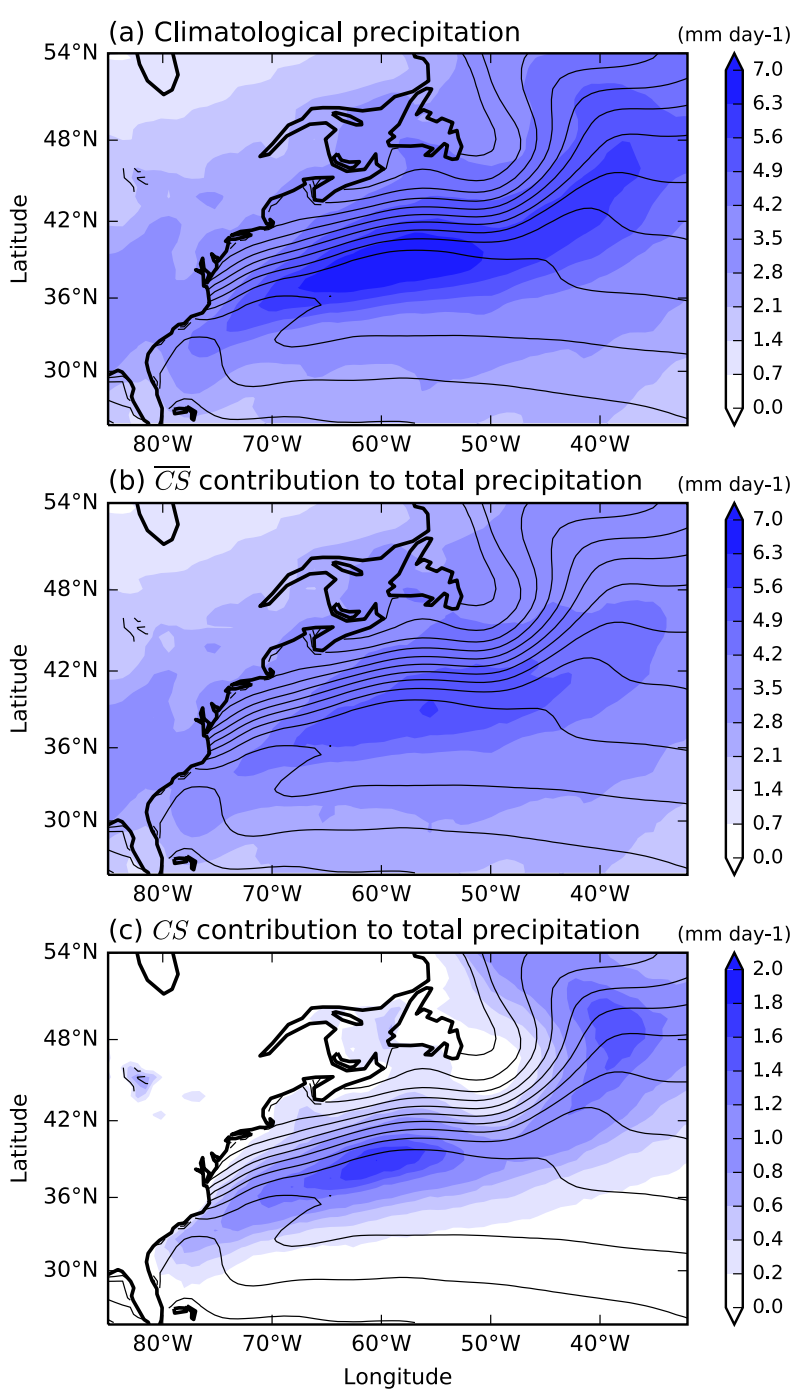

Figure 5. ERA Interim DJF precipitation $\left(\mathrm{mm} \mathrm{day}^{-1}\right.$ ) (a) climatological mean, (b) contribution to climatological mean precipitation from outside the cold sector $\left(\mu_{\mathrm{CS}}(P)\right),(\mathrm{c})$ contribution to climatological mean precipitation from the cold sector $\left(\mu_{C S}(P)\right)$. 6-hourly data are used. 

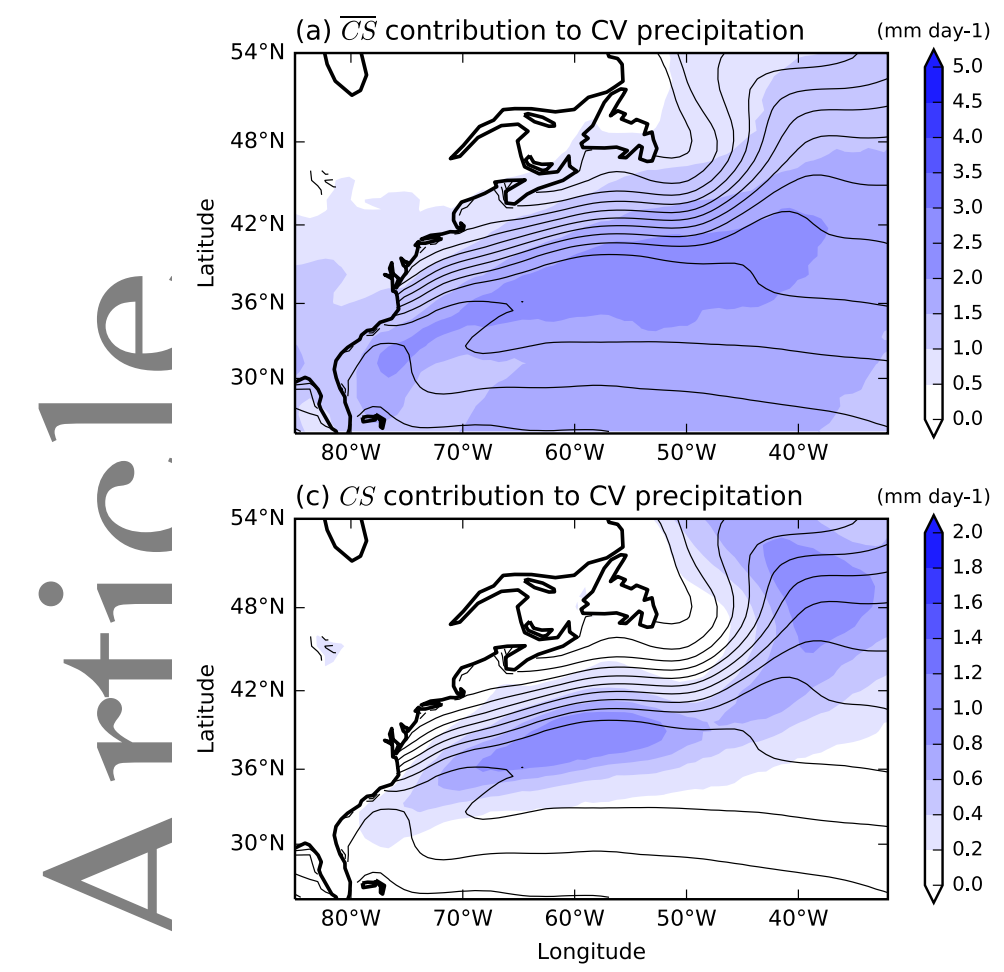
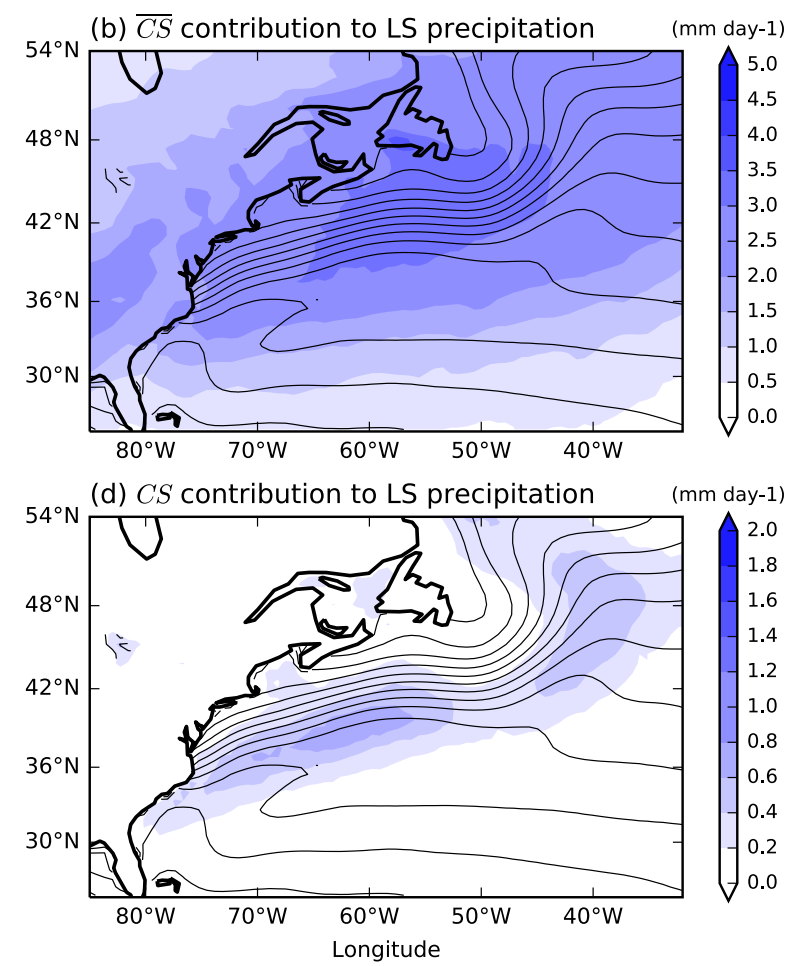

Figure 6. ERA Interim DJF precipitation decomposed as precipitation in convective (a,c) and large scale (b,d) occurring in $\overline{C S}$ (a,b) and $C S$ (c,d). 6-hourly data are used.
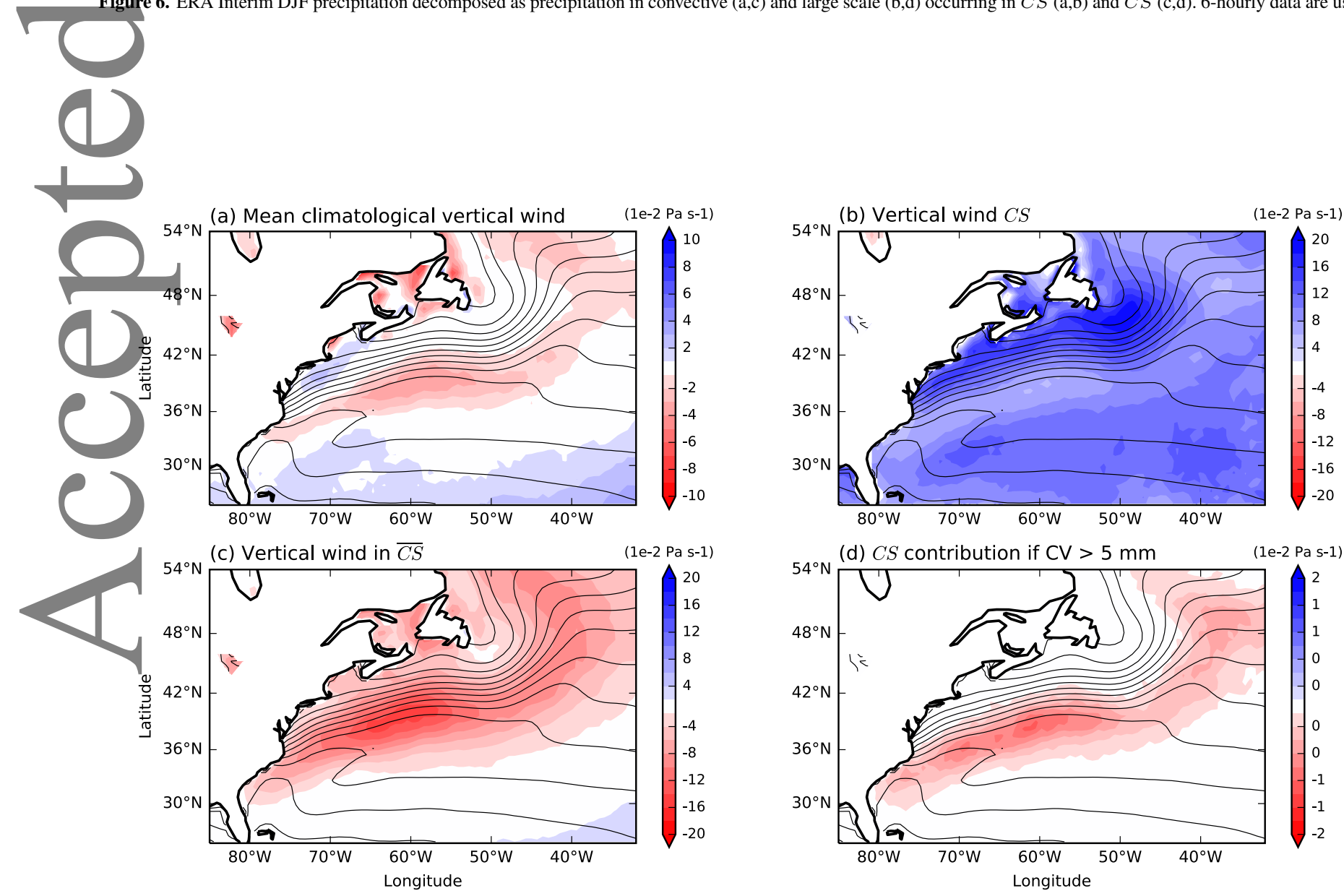

Figure 7. DJF vertical wind in pressure coordinates at $700 \mathrm{hPa}\left(P a . s^{-1}\right)$ : (a) climatological mean, (b) mean of the cold sector situations, i.e. $m_{C S}\left(\omega_{700}\right)$, (c) mean of non cold sector situations, i.e. $m_{\overline{C S}}\left(\omega_{700}\right)$, (d) contribution of cold sector to total wind when convective precipitation is above 5 mm day ${ }^{-1}$, i.e. $\mu_{C S}\left(\omega_{700}\right)$ when convective precipitation is larger than $5 \mathrm{~mm} \mathrm{day}^{-1}$. 6-hourly data are used.

This article is protected by copyright. All rights reserved. 

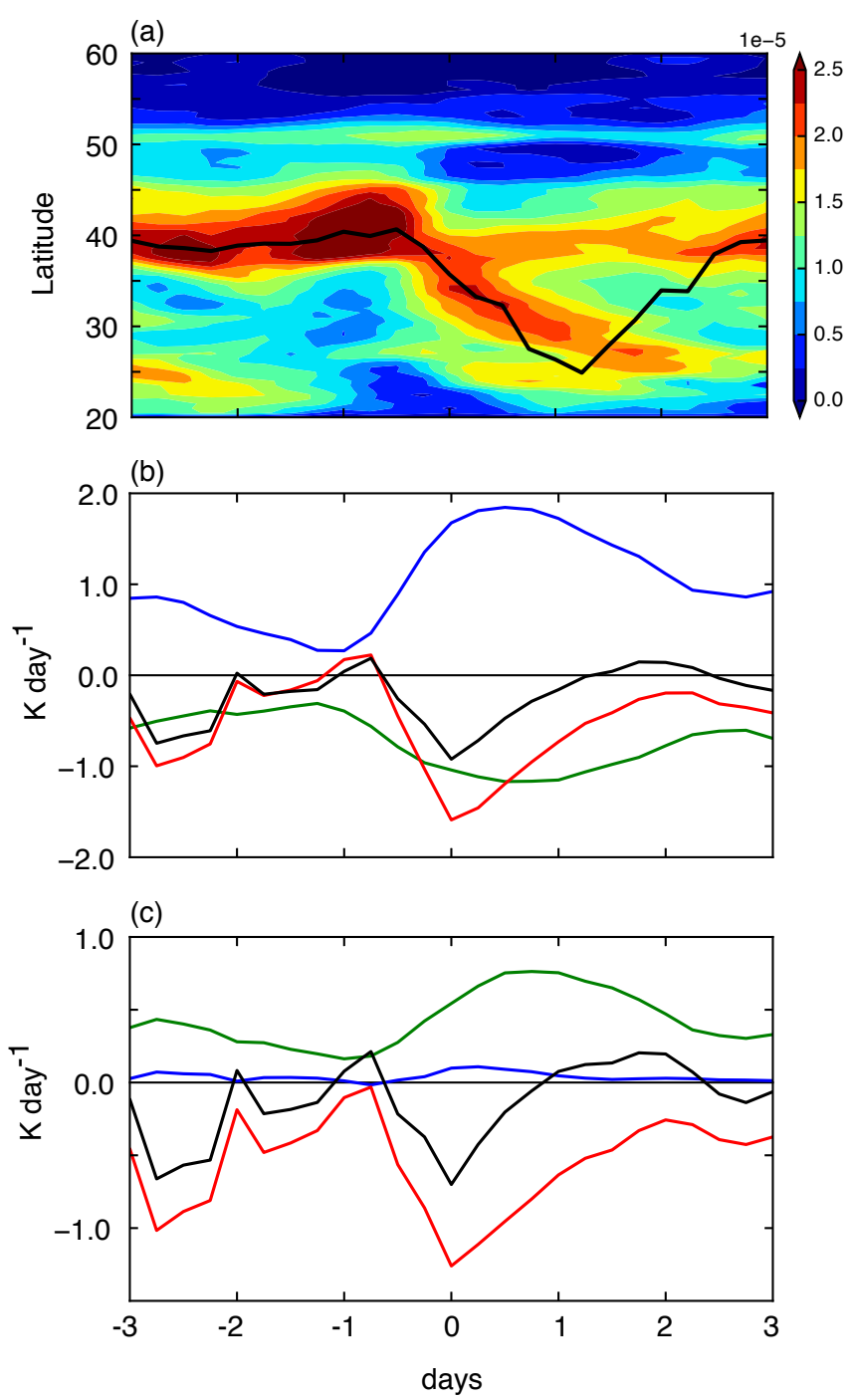

Legend for panels (b) and (c) :

- total convection - BL diffusion — dynamics

Figure 8. (a) Hoevmoller diagram of $\partial_{y e}$ (colour field in $\mathrm{K} \mathrm{m}^{-1}$ ) zonally averaged between 70 and $60{ }^{\circ} \mathrm{W}$ for a composite of 45 extratropical cyclones; overlaid in black contours is the mean latitude of the maximum of $\partial_{y} \theta_{e}$. Events are selected to be part of the composite if they belong to the lowest $15 \%$ of sea-level pressure and highest $15 \%$ of meridional eddy heat flux in the box $\left[60-50^{\circ} \mathrm{W}, 30-50^{\circ} \mathrm{N}\right]$. The composite is centred around the detection time. For the same composite, the bottom two panels show $\Delta_{S / N} \dot{\theta}_{e}$ vertically averaged between (b) 1000 and $850 \mathrm{hPa}$ and (c) 850 and $700 \mathrm{hPa}$; colours stand for the total tendency (black) and tendencies due to advection (red), boundary layer diffusion (blue) and convection (green). 
(a) Mean baroclinicity

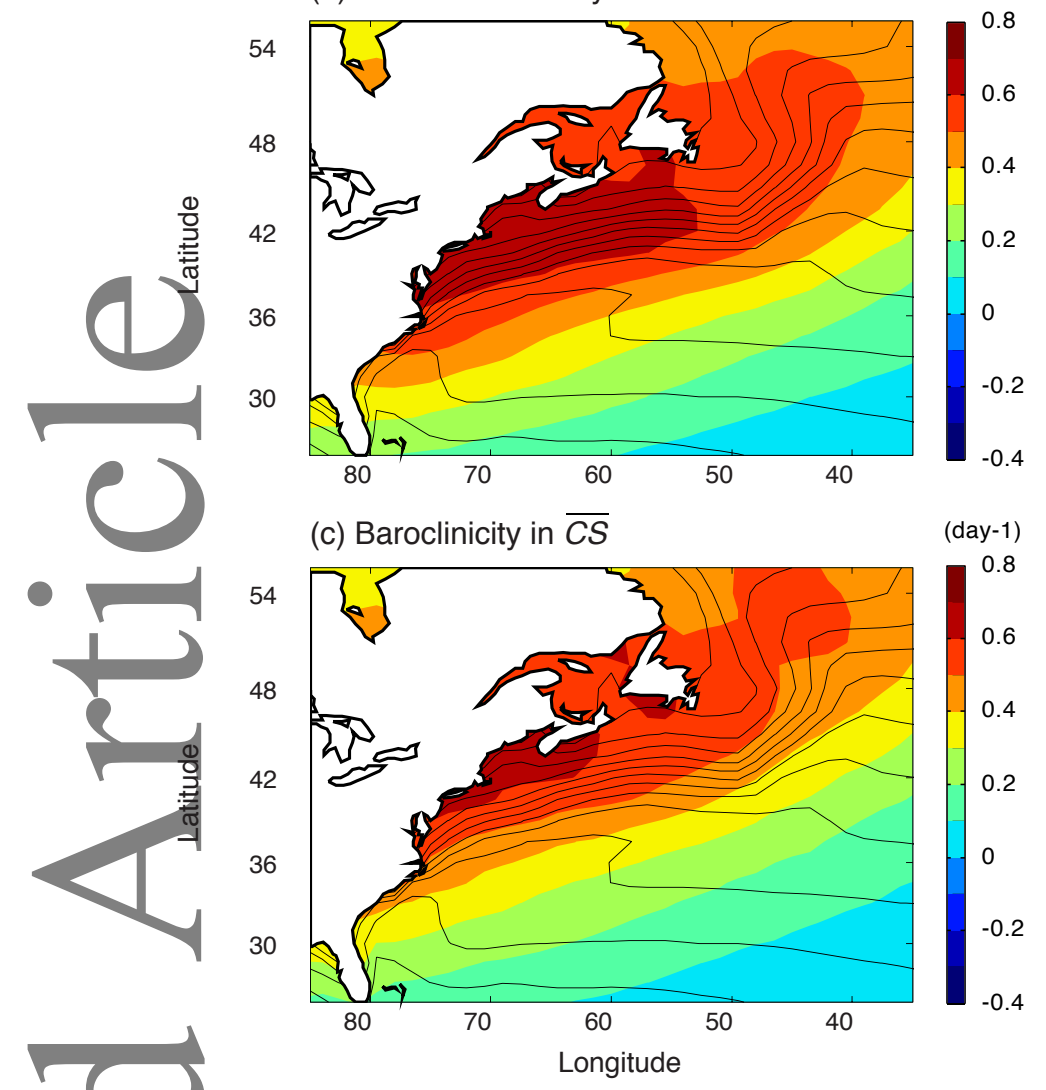

(b) Baroclinicity in CS

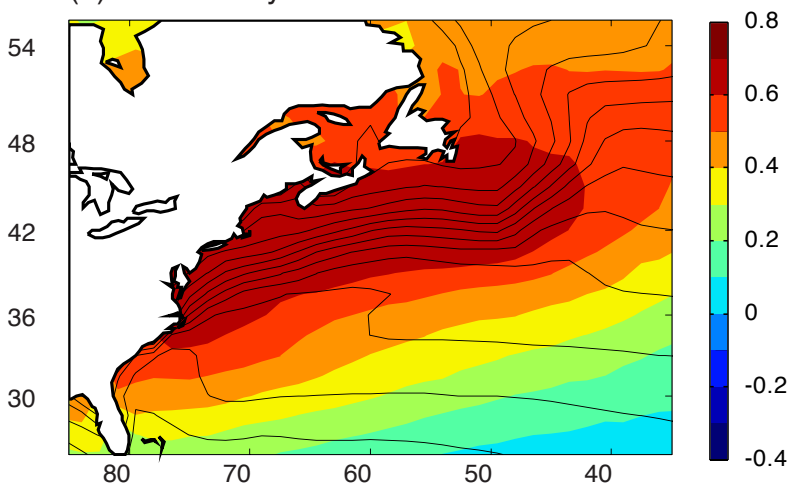

(d) Baroclinicity $C S-\overline{C S}$

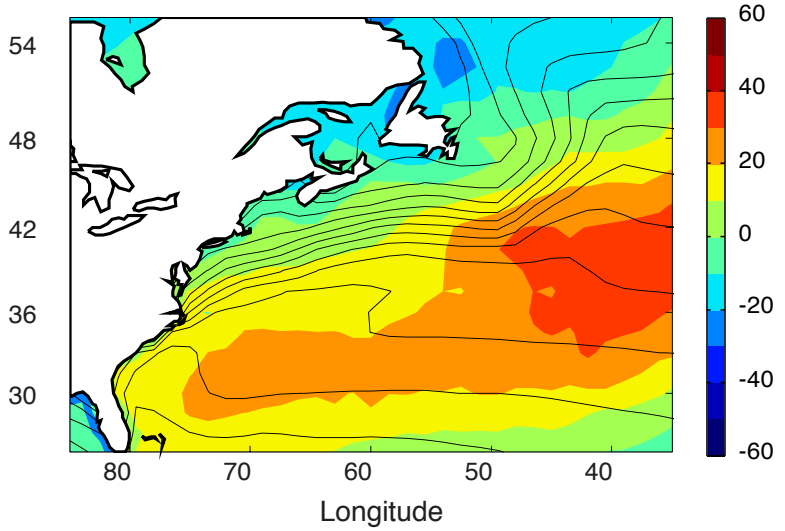

Figure 9. Eady parameter $\left(d a y^{-1}\right)$ : (a) climatological mean, (b) mean of the cold sector situations, i.e. $m_{C S}(\sigma)$, (c) mean of non cold sector situations, i.e. $m_{\overline{C S}}(\sigma)$. (d) Percentage change of Eady parameter between $C S$ and $\overline{C S}$, i.e. between $m_{C S}(\sigma)$ and $m_{\overline{C S}}(\sigma)$. SST is shown in black contours (every $2 \mathrm{~K}$ ).

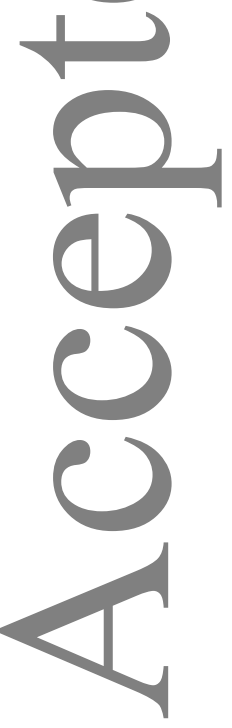

(a)

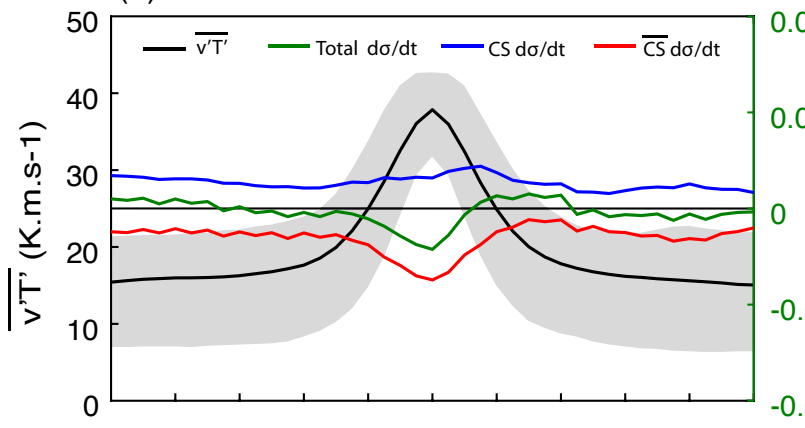

0.04

0.02

\section{0}

0.02

(b)

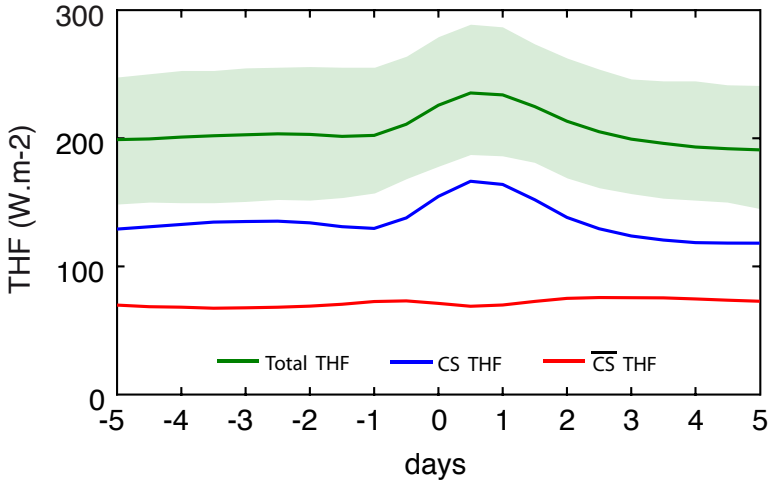

Figure 10. (a) Evolution for a composite centred around time maxima of meridional eddy heat fl uxes at $850 \mathrm{hPa}$ (black curve and its interquartile range in black shadings) of the tendency of baroclinicity at $775 \mathrm{hPa}$ (green curve, in $\left.d a y^{-1}(6 \text { hours })^{-1}\right)$, the contribution of cold sector situations to tendency of baroclinicity, i.e. $\mu_{C S}(\sigma)$, (blue curve) and the contribution of non cold sector situations, i.e. $\mu \overline{C S}(\sigma)$ (red curve); (b) evolution for the same composite of total heat fl ux (green) and its interquartile range (green shadings), contribution of cold sector situations to total heat fl ux, i.e. $\mu_{C S}(T H F)$, (blue curve) and contribution of non cold sector situations, i.e. $\mu_{C S}(T H F)$, (red curve). All quantities are averaged over the domain $\left[80^{\circ} \mathrm{W}-30^{\circ} \mathrm{W}, 30^{\circ} \mathrm{N}-50^{\circ} \mathrm{N}\right]$.

This article is protected by copyright. All rights reserved. 


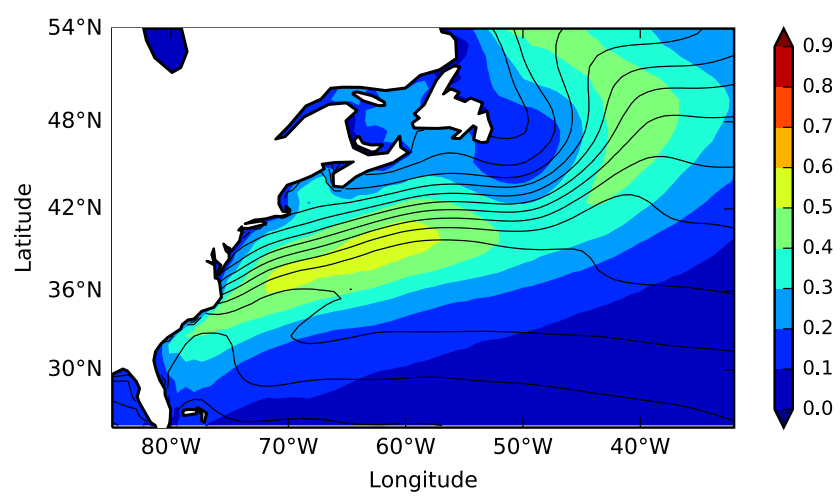

Figure 11. Frequency of detection of the cold sector with the mask combining PV and sensible heat flux (read section 2.2 for a description of the mask) and SST (black

contours every $2 \mathrm{~K}$ ).
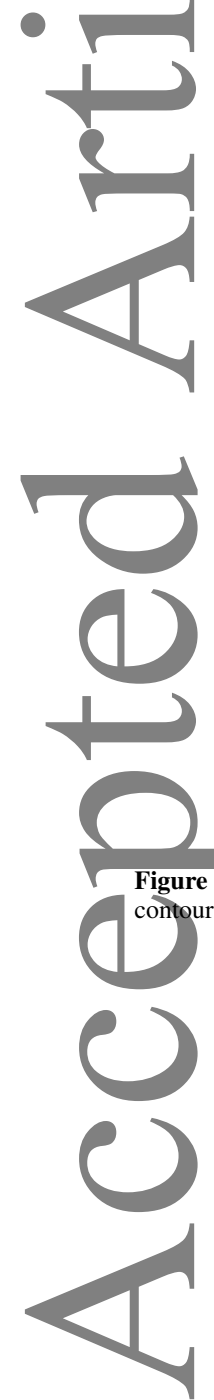

This article is protected by copyright. All rights reserved. 